\title{
Cytotoxicity of Ferulic Acid on T24 Cell Line Differentiated by Different Microenvironments
}

\author{
Chiung-Chi Peng, ${ }^{1}$ Charng-Cherng Chyau, ${ }^{2}$ Hui-Er Wang, ${ }^{3}$ Chi-Huang Chang, ${ }^{2}$ \\ Kuan-Chou Chen, ${ }^{4}$ Kuang-Yu Chou, ${ }^{5}$ and Robert Y. Peng ${ }^{2}$ \\ ${ }^{1}$ Graduate Institute of Clinical Medicine, College of Medicine, Taipei Medical University, 250 Wu-Hsing Street, Taipei 11031, Taiwan \\ ${ }^{2}$ Research Institute of Biotechnology, Hungkuang University, 34 Chung-Chie Road, Shalu County, Taichung 43302, Taiwan \\ ${ }^{3}$ Department of Food and Applied Biotechnology, Hungkuang University, 34 Chung-Chie Road, Shalu County, \\ Taichung 43302, Taiwan \\ ${ }^{4}$ Department of Urology, School of Medicine, College of Medicine, Taipei Medical University, 250 Wu-Hsing Street, Taipei 11031, Taiwan \\ ${ }^{5}$ Division of Urology, Department of Surgery, Shin Kong Wu Ho-Su Memorial Hospital, 95 Wen Chang Road, Taipei 111, Taiwan
}

Correspondence should be addressed to Kuan-Chou Chen; kc.chen416@msa.hinet.net, Kuang-Yu Chou; ky_chou@livemail.tw, and Robert Y. Peng; ypeng@seed.net.tw

Received 18 September 2012; Revised 23 February 2013; Accepted 23 February 2013

Academic Editor: Fabio Ferreira Perazzo

Copyright (c) 2013 Chiung-Chi Peng et al. This is an open access article distributed under the Creative Commons Attribution License, which permits unrestricted use, distribution, and reproduction in any medium, provided the original work is properly cited.

Ferulic acid (4-hydroxy-3-methoxycinnamic acid) (FA) is a ubiquitous health beneficial phenolic acid. Although FA has shown a diversity of biological activities including anti-inflammatory, antihypercholesterolemic and anticancer bioactivities, studies revealing its adverse effects are accumulating. Recently, 3D-cultures are shown to exhibit uniquely biological behaviors different from that of 2D cultures. To understand whether the cytotoxicity of FA against the T24 cell line (a bladder cancer cell line) in 2Dculture could consistently retain similar bioactivity if cultured in the 3D-systems, we conducted this experiment with 2 mM FA. Much higher cytotoxicity was found for 3D- than 2D-culture, showing (2D vs. 3D): apoptotic rates, $64 \%$ and $76 \%$; cell killing rates, $3.00 \times 10^{5}$ cells $\mathrm{mmol}^{-1} \cdot \mathrm{h}^{-1}$ and $2.63 \times 10^{6} \mathrm{cells} \mathrm{mmol}^{-1} \cdot \mathrm{h}^{-1}$, attaining a 8.77 -fold. FA upregulated the activities at $72 \mathrm{~h}(2 \mathrm{D}$ vs. $3 \mathrm{D}$ in folds that of control): SOD, 1.73 -folds $(P<0.05)$ versus 3.18 folds $(P<0.001)$; and catalase, 2.58 versus 1.33 -folds. Comparing to the control (without FA), Bcl-2 was prominently downregulated while Bax, caspase- 3 and cleaved caspase- 9 were more upregulated in 3D-cultures $(P<0.05)$. Conclusively, different microenvironments could elicit different biological significance which in part can be ascribed to different mass transport rate.

\section{Introduction}

Ferulic acid (4-hydroxy-3-methoxycinnamic acid) (FA), an effective component of many Chinese medicinal herbs like Angelica sinensis, Cimicifuga heracleifolia, and Lignsticum chuangxiong, is a ubiquitous phenolic acid in the plant kingdom [1]. FA exhibits many physiological functions including antioxidant, antimicrobial, anti-inflammatory, antithrombosis, antihypercholesterolemic, anticancer activities, and spermatozoa activating bioactivity [1]. Interest in the role of flavonoids to act as health benefits is emerging owing to their potential biological activities. However, to date, epidemiologic studies exploring the role of flavonoids in human health have been inconclusive [2]. Some studies supported the protective effect of flavonoids on cardiovascular disease and cancer, others demonstrated no effect [2], and interestingly a few suggested them to be potentially harmful [3]. More recently, we demonstrated FA to be nephrodamaging when used for a long-term treatment for chronic kidney disease (CKD) [4].

Conventional adherent tissue culture involves growing cells on solid flat surfaces as two-dimensional (2D) monolayers. Although such practices are routine and suitable for transformed or immortalized cell lines, dedifferentiation and loss of specialized functions occur when primary cells are removed from their host tissue and grown as 2D monolayers. 
This is generally believed to be a result of the dissociation of primary cells from their native three-dimensional structure in vivo to their two-dimensional propagation on flat impermeable substrates in vitro [5-7]. As such, there is a continuing need to develop tissue culture systems which can either promote redifferentiation of laboratory cell lines or prevent primary cell lines from dedifferentiating.

The reason(s) eliciting different biological outcomes by different microenvironments is still unclear. With an aim to understand more about the cellular physiology and conversely the different cytotoxicity of a given flavonoid like FA that may occur in different microenvironments as specified by the $2 \mathrm{D}$ and $3 \mathrm{D}$ cultures, we carried out this present study. We compared the cell viability, the cellular morphology, the oxidative stress defensive markers, and the apoptotic and antiapoptotic signals between the $2 \mathrm{D}$ and $3 \mathrm{D}$ cultures in the T24 cell line (a balder cancer cell line). For interpretation we developed a diagrammatic model to emphasize the mass transport in part to be an important role affecting such an outcome.

\section{Materials and Methods}

2.1. Chemicals and Kits. Ferulic acid (FA) was supplied by Sigma Aldrich (Saint Louis, MO, USA). The medium McCoy's 5A was provided by (GIBCO, USA), which was supplemented with $10 \%$ fetal bovine serum (FBS) (GIBCO, USA), $100 \mathrm{IU} / \mathrm{mL}$ penicillin, and $100 \mu \mathrm{g} / \mathrm{mL}$ streptomycin (GIBCO, USA). The $\mathrm{pH}$ of $2 \mathrm{D}$ culture was unadjusted after incubation, while that of 3D cultures was controlled through $\mathrm{CO}_{2}$ atmosphere. The fixing solution was prepared by dissolving glutaraldehyde $(2.5 \mathrm{~g})$ and paraformaldehyde $(2 \mathrm{~g})$ in $100 \mathrm{~mL}$ of $0.2 \mathrm{M}$ of sodium cacodylate (CaCo). The washing buffer was prepared by dissolving $7 \mathrm{~g}$ of sucrose in $100 \mathrm{~mL}$ of $0.1 \mathrm{M} \mathrm{CaCO}$. Ferulic acid (FA) stock solution was prepared by dissolving authentic ferulic acid in DMSO to make a $2 \mathrm{M}$ solution (stock solution). The required experimental solutions were prepared by diluting the stock solution with appropriate amount of medium McCoy's $5 \mathrm{~A}$ to the experimental concentrations as indicated. Antibodies Bcl-2 $(1: 1000)$, Bax $(1: 1000)$, cleaved caspase-3 $(1: 1000)$, cleaved caspase-9 $(1: 1000)$, and $\beta$-actin $(1: 1000)$ were purchased from Bioscience Co. (United Kingdom).

2.2. Cells. The human urinary bladder cancer cell line, T24 (HTB-4, ATCC), was purchased from the Food Industry Research and Development Institute (Hsinchu, Taiwan, ROC). T24 cells were derived from an invasive bladder tumor of grade 3 , having $p 53$ nonsense mutation at codon 126 (TAC to TAG) $[8]$.

\subsection{Cell Culture}

2.3.1. D Culture of T24 Cell Line. According to the method of [9], T24 cells at a density of $2 \times 10^{4}$ cells $/ \mathrm{mL}$ were seeded onto a 6-well plate in medium McCoy's $5 \mathrm{~A}$ containing $2 \mathrm{mM}$ FA. The cells were incubated at $37^{\circ} \mathrm{C}$ in a humidified atmosphere containing $5 \% \mathrm{CO}_{2}$ in air for $24 \mathrm{~h}$. The cultivation of T24 cells was maintained within 20 passages. These cells were further used for cultivation in RWV.

2.3.2. 3D Culture of T24 Cell Line. The T24 cells were harvested from the $2 \mathrm{D}$ plate culture. By following the manufacturer's instructions, the cell count was enumerated and inoculated at $2 \times 10^{5}$ cells $/ \mathrm{mL}$ to the $50 \mathrm{~mL}$ spinner vessel (Techne) of the Rotary Cell Culture System (RCCS) (Synthecon Co., Houston, TX, USA), which has been always referred to as the three-dimensional rotating-wall vessel (RWV) [10]. CultiSpher-G was prepared according to instructions and the amount used was either $2 \mathrm{~g} / \mathrm{L}$ (Vero) or $1 \mathrm{~g} / \mathrm{L}$ (GMK). Medium McCoy's 5A was used to fill up the entire vessel to get rid of the air. The RWV containing the medium and cells was incubated at $37^{\circ} \mathrm{C}$ at an agitation speed $45 \mathrm{rpm}$. The incubation was continued and the medium was replaced every 2 days together with $25 \mathrm{~mL}$ of sterilized FA ( $4.0 \mathrm{mM})$ solution to sustain the FA concentration at $2 \mathrm{mM}$. On day 3 , the cells were harvested and transferred into a centrifuge tube and centrifuged at $10000 \times \mathrm{g}$ for $10 \mathrm{~min}$. The supernatant was decanted. The cell cluster was rinsed thrice with sterilized PBS, each time with $20 \mathrm{~mL}$.

2.4. SEM Examination of Morphological Changes. The cells were diverged in the fixing fluid for $2 \mathrm{~h}$ and then centrifuged. The fixing fluid was decanted off. The residual cells were rinsed with washing buffer thrice, each time for $10 \mathrm{~min}$. The rinsed cells were remained in the rinsing solution until SEM scanning. $1 \mu \mathrm{L}$ of the sample was measured from the sampling port of RCCS. Cryofixation of the suspension was finished in HPM 010 high Pressure Freezing Machine (TESCAN, USA). Graphene support films for electron microscopy (Electron Microscopy Sciences) were used. The specimens were uniformly coated with one layer gold powder using EMS 150R boast (Electron Microscopy Sciences). EM image was taken by the transmission electron microscope (DELONG TEM LVEM5) operated at an accelerating voltage $100 \mathrm{kV}$. The aperture was set at "1" with a motorized JSM-840A (Deben) to fit the TEM console. The electron gun was made of lanthanum hexaboron operated at $1500 \mathrm{~K}$.

\subsection{Cell Viability Assay}

2.5.1. MTT Assay for 2D Culture. According to the method described by [9], T24 cells were seeded at a density of $5 \times$ $10^{3}$ cells/well onto a 24 -well plate, treated with FA (DMSO vehicle, 2 and $4 \mathrm{mM}$ ), and incubated at $37^{\circ} \mathrm{C}$ in a humidified atmosphere containing $5 \% \mathrm{CO}_{2}$ in air for 24,48 , and $72 \mathrm{~h}$. To each well $0.2 \mathrm{~mL}$ of MTT was added and the cultivation was continued for additional $3.5 \mathrm{~h}$. The MTT solution was removed by sucking off, and $0.5 \mathrm{~mL}$ DMSO was added to dissolve the blue formazan precipitate. After $10 \mathrm{~min}$, the optical density was read at $570 \mathrm{~nm}$ and the cell viability was evaluated.

2.5.2. Cell Enumeration for 3D Culture. Following the manufacturer's instructions, duplicate samples of $0.5 \mathrm{~mL}$ were taken from the spinner. After sedimentation of the beads, $0.3 \mathrm{~mL}$ supernatant was withdrawn and $0.8 \mathrm{~mL}$ dispase 
$(5 \mathrm{mg} / \mathrm{mL}$ in PBS) was added. Beads were completely dissolved after $30 \mathrm{~min}$ at $37^{\circ} \mathrm{C}$. Cells were collected by centrifugation at $12000 \times \mathrm{g}$ and $1.0 \mathrm{~mL}$ of citric acid $(0.1 \mathrm{M})$ containing Triton X-100 (1\%, w/v) and crystal violet $(0.01 \%, \mathrm{w} / \mathrm{v})$ added. Stained nuclei were counted in a hematocytometer (Percell Biolytica Application Note 115).

2.6. ELISA for Serum Superoxide Dismutase and Catalase. The levels of superoxide dismutase (SOD) and catalase were measured by the SOD and catalase ELISA Kits provided by PeproTech Inc. (NJ, USA). All ELISA protocols were performed according to manufacturer's instructions. The readings were conducted with the SYSMEX K-1000 Reader, a product of San-Tong Instrument Co. (Taipei, Taiwan).

2.7. Western Blotting. The cells (approximately $100 \mathrm{mg}$ ) obtained in the above were homogenized with the homogenizer (T10 basic, The IKA Company, Germany) in $1 \mathrm{~mL}$ of ProPREP lysis buffer ( $\mathrm{pH}$ 7.2). The homogenate was centrifuged at $12000 \times \mathrm{g}$ for $20 \mathrm{~min}$ at $4^{\circ} \mathrm{C}$, and the supernatant was collected as cell lysate sample. The cell lysate was heated at $100^{\circ} \mathrm{C}$ for $10 \mathrm{~min}$ before loading and separated on precasted $7.5 \%$ SDS-PAGE. The protein content was analyzed before loading according to the manufacturer's instructions. Aliquots of the treated lysates containing protein $50 \mu \mathrm{g} / \mu \mathrm{L}$ were electrotransferred onto the PVDF membrane in transfer buffer for $1 \mathrm{hr}$. The nonspecific binding to the membrane was blocked for $1 \mathrm{hr}$ at room temperature with 5\% nonfat milk in TBS buffer. The membranes were then incubated for $16 \mathrm{hr}$ at $4^{\circ} \mathrm{C}$ with various primary antibodies. After extensive washing in TBS buffer, the membranes were then incubated with secondary antibody in blocking buffer containing 5\% nonfat milk for $1 \mathrm{hr}$ at room temperature. Membranes were then washed with TBS buffer, and the signals were visualized using the Luminescent Image Analyzer LAS-4000 (Fujifilm, Tokyo, Japan). Levels of Bcl-2, Bax, cleaved caspase-9, cleaved caspase-3, and $\beta$ actin were assayed, respectively, by immunoassay according to the manufacturers' instructions. $\beta$-actin was used as the reference protein.

2.8. Statistical Analysis. Data obtained in the same group were analyzed by Student's $t$-test with computer statistical software SPSS 10.0 (SPSS, Chicago, IL, USA). ANOVA software statistical system was used with Tukey's testing to analyze the variances and significances of difference between paired means. Significance of difference was judged by a confidence level of $P<0.05$.

\section{Results and Discussions}

3.1. SEM Scanning Revealed Ferulic Acid and 3D Microenvironment Induced Cell Elongation. In the absence of FA, T24 cells proliferated equally well despite 2D (Figure 1(a)) or 3D (Figure 1(c)) cultures. The presence of FA (2 mM) slightly elongated the cell shape, and in parallel the cell number was largely reduced (Figure 1(b)). The majority of the cells died after being cultivated for $72 \mathrm{~h}$ at $37^{\circ} \mathrm{C}$ in both $2 \mathrm{D}$ and $3 \mathrm{D}$ cultures. The dead cells on the $3 \mathrm{D}$ matrix appeared puffy, elongated, and not well shaped (Figure 1(d)).
3.2. Cell Viability Affected by Ferulic Acid and Microenvironment. The viability of $\mathrm{T} 24$ cell line was seen inhibited in time-responsive manner in the presence of $2 \mathrm{mM}$ FA. In $2 \mathrm{D}$ culture, the cell viability was reduced to 72,53 , and $36 \%$, respectively, compared to the control (Figure $2(\mathrm{a})$ ). The corresponding values reached 63,32 , and $24 \%$, respectively (Figure 2(b)). The killing rate in $2 \mathrm{D}$ culture was found to be $3 \times 10^{5}$ cells $\mathrm{mmol}^{-1} \cdot \mathrm{h}^{-1}$. More severe killing rate in the $3 \mathrm{D}$ cultures reached $2.63 \times 10^{6}$ cells $\mathrm{mmol}^{-1} \cdot \mathrm{h}^{-1}$, giving a difference of 8.77 -fold.

Cherng et al. indicated that FA ( $4 \mathrm{mM})$ effectively suppressed the proliferation of $\mathrm{J} 82$ cells, another bladder cancer cell line, to a viability $48.79 \%$ [9]. In contrast to our data, $64 \%$ of T24 cells in the $2 \mathrm{D}$ and $76 \%$ in the $3 \mathrm{D}$ cultures were killed by ferulic acid $(2 \mathrm{mM})$ after being incubated for $72 \mathrm{~h}(P<0.01)$ (Figures 1 and 2$)$, evidently implicating the astonishing effect caused by different microenvironments. Alternatively, different cell lines responded differently to the same phytochemical in equal strength even in the $2 \mathrm{D}$ culture [10]. Thus, the outcome of chemicobiological interaction depends not only on the microenvironmental factor but also on the cell genotypes.

Rhee demonstrated nonrandom genetic and phenotypic changes in prostate epithelial cells. The occurrence of such permanent changes may be highly contact dependent and appears to be driven by specific microenvironmental factors surrounding tumor cell epithelium grown as $3 \mathrm{D}$ prostate organoids [11].

Why could 3D culture exhibit a higher killing rate? This part will be discussed in Section 3.6.

3.3. Effect of Ferulic Acid on the Superoxide Dismutase and Catalase Activities. The activity of SOD was upregulated by FA in $2 \mathrm{D}$ and $3 \mathrm{D}$ cultures, increasing approximately to $1.73-$ fold $(P<0.050)$ and 3.18-fold $(P<0.001)$, respectively (Figure 3(a)). Conversely the catalase activity was highly induced by $2 \mathrm{D}$ but only slightly significant by $3 \mathrm{D}$ cultures. The increase reached 2.58-fold for 2D and 1.33-fold for 3D cultures (Figure 3(b)).

Superoxide is one of the main reactive oxygen species (ROS) in the cells. Approximately $0.4-4 \%$ of all oxygen consumed during normal respiration is converted into superoxide within the mitochondrion [12], the chief source of reactive oxygen species (ROS) within the cell. Superoxide dismutases (SOD, EC1.15.1.1) are enzymes that catalyze the dismutation of superoxide into oxygen and hydrogen peroxide. Thus, they are an important antioxidant defense in nearly all cells exposed to oxygen [13]. It is simply stated that SOD outcompetes damaging reactions of superoxide, thus protecting the cell from superoxide toxicity [14]. Superoxide is known to denature enzymes, oxidize lipids, and fragment DNA. SODs catalyze the production of $\mathrm{O}_{2}$ and $\mathrm{H}_{2} \mathrm{O}_{2}$ from superoxide $\left(\bullet \mathrm{O}_{2}{ }^{-}\right)$, which results in less harmful reactants. When acclimating to increased levels of oxidative stress, SOD concentrations typically increase with the degree of stress conditions [15].

Catalase is one of the most potent catalysts known. The reactions it catalyses are crucial to life. Catalase catalyses 
Ferulic acid (-)

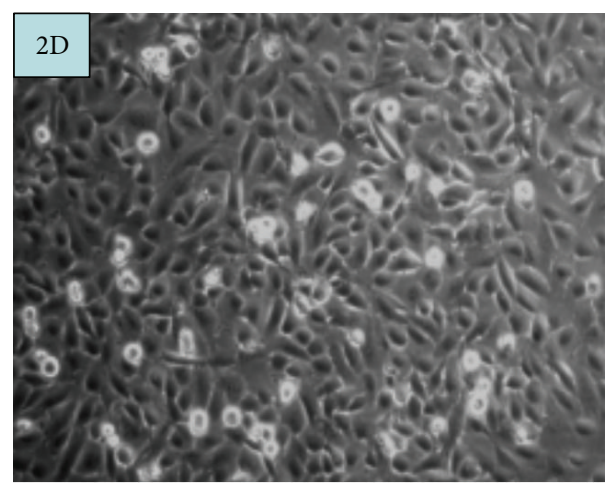

(a)

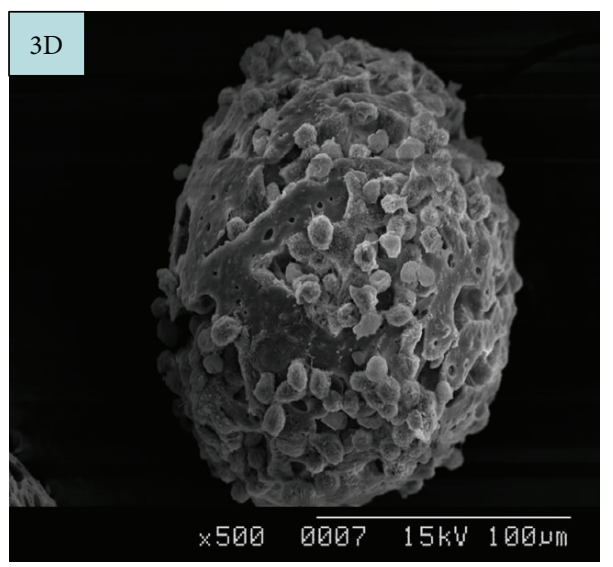

(c)
Ferulic acid (2 mM)

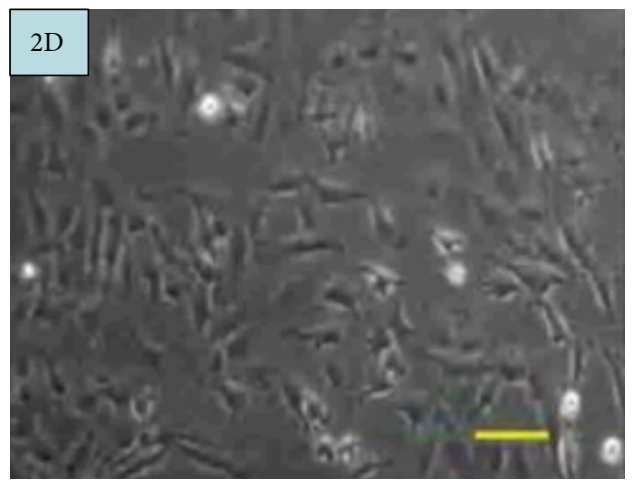

(b)

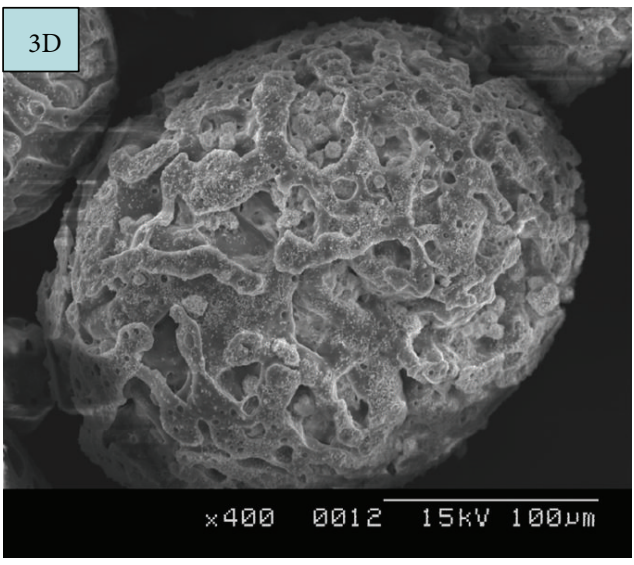

(d)

FIGURE 1: SEM scanning of the T24 cell morphology affected in the absence and presence of $2 \mathrm{mM}$ ferulic acid in 2D and 3D cultures. 2D culture: control (a); $2 \mathrm{D}+$ ferulic acid $2 \mathrm{mM}$ (b) (magnification $\times 500$, scale bar $=0.1 \mathrm{~mm})$. 3D culture: control (c) $($ magnification $\times 500) ; 3 \mathrm{D}+$ ferulic acid $2 \mathrm{mM}(\mathrm{d})$ (magnification $\times 400)$. Cultivation time was $72 \mathrm{~h}$ at $37^{\circ} \mathrm{C}$ for $2 \mathrm{D}$ and $3 \mathrm{D}$ cultures, respectively.

conversion of hydrogen peroxide, a powerful and potentially harmful oxidizing agent, to water and molecular oxygen. Hydrogen peroxide is a harmful by-product of many normal metabolic processes: to prevent damage to cells and tissues, it must be quickly converted into other, less dangerous substances. To this end, catalase is frequently used by cells to rapidly catalyze the decomposition of hydrogen peroxide into less reactive gaseous oxygen and water molecules [16]. Catalase also uses hydrogen peroxide to oxidize toxins including phenols and alcohols [17]. Catalase is essential to protect the stability of ferrous ion-requiring enzymes both in vitro and in vivo systems [18]. Hydrogen peroxide has recently been shown to inactivate the enzyme by oxidation of crucial cysteines [19].

Alternatively, space microenvironment could play an important role in balancing these antioxidative enzymes. Speculatively, the synergistic interaction of SOD and catalase was effectively operating in the T24 cells and obviously there might have been much higher ROS occurring in the 2D culture, as evidenced by the highly raised catalase activity (Figure 3(b)). The major part of superoxide anions produced could have been consumed through the NO pathway by the huge amount of NO otherwise produced (not shown); hence the apparent level of SOD was highly suppressed in the 2D cultures (Figure 3(a)). Such a case was not seen in the 3D culture. In $3 \mathrm{D}$ culture, the T24 cells were freely rotating with the matrix and had much larger space for cell proliferation. Consequently, the ROS produced could rapidly diffuse out the cells, immediately diluted by the bulk fluid around the cells. The lower catalase activity found for the 3D culture may give a strong support to this (Figure 3(b)).

3.4. Western Blot Indicated 3D Culture Showed Stronger Apoptotic Effect than 2D Culture. As seen, the antiapoptotic cytokine $\mathrm{Bcl}-2$ was suppressed by $3 \mathrm{D}$ to 0.5 -fold compared with 0.80 -fold by the $2 \mathrm{D}$ and 1.00 -fold in the control. Conversely, the proapoptotic cytokine Bax was similarly upregulated by $3 \mathrm{D}$ and $2 \mathrm{D}$, reaching 1.45 - and 1.40 -fold, respectively, compared with the control, 1.00-fold. Alternatively, the cleaved caspase- 9 and cleaved caspase- 3 were all substantially upregulated by $3 \mathrm{D}$ and $2 \mathrm{D}$ cultures. However it is worth noting that cleaved caspase-3 was more evidently induced by $3 \mathrm{D}$ than $2 \mathrm{D}$ cultures (Figure 4). Results implicated that $3 \mathrm{D}$ culture exhibited higher cytotoxicity than $2 \mathrm{D}$ identity. 


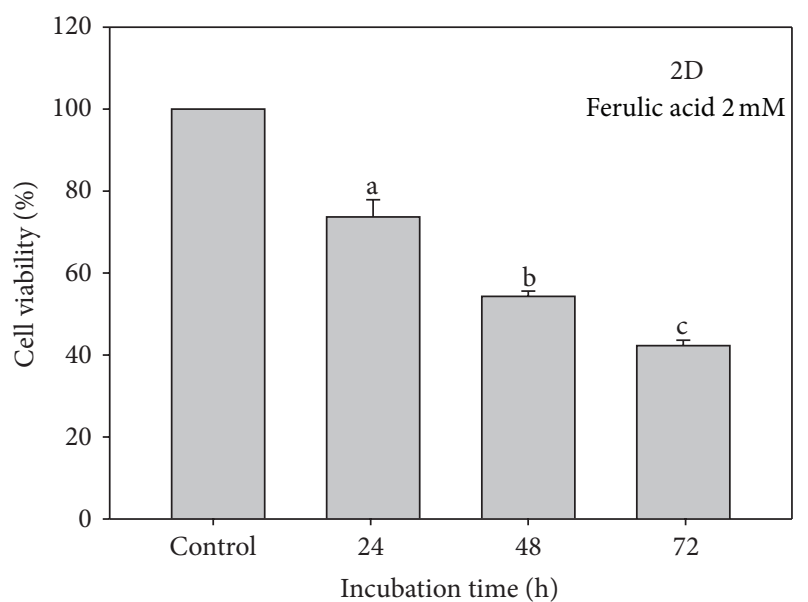

(a)

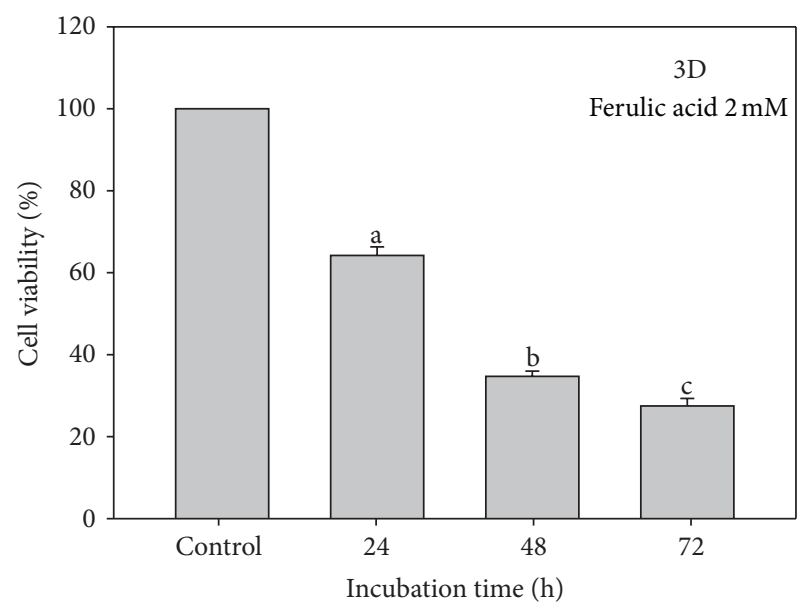

(b)

FIGURE 2: Comparison of cell viability of T24 cell lines in the presence of ferulic acid. 2D culture (a) and 3D culture (b). The concentration of ferulic acid used was $2 \mathrm{mM}$. The cultivation was conducted at $37^{\circ} \mathrm{C}$ for 24,48 , and $72 \mathrm{~h}$, respectively. Data was expressed in mean \pm SD from triplicate experiments $(P<0.05)$.

3.5. Intrinsic Mitochondrial Pathway Was Involved in Apoptosis. Western blotting revealed the Bcl-2 level was more prominently downregulated by 3D $(P<0.05)$; conversely, the levels of Bax, cleaved caspase-3, and cleaved caspase9 were all significantly upregulated in $2 \mathrm{D}$ and $3 \mathrm{D}$ cultures $(P<0.05)$, comparatively, upregulated slightly higher in $3 \mathrm{D}$ culture (Figure 4), an implication in the higher extent of apoptosis occurring in 3D culture (Figure 2).

3.6. Difference in Mass Transport in Part Can Impart the Causality of Cell Death. To interpret the difference of the microenvironmental factor, we established the diagrammatic figure to show the difference of mass transport in these two cultures (Figure 5). The mass transport in 2D culture is limited by two barriers: "the stagnant region" and "the cell membrane" [20] (Figures 5(a) and 5(b)). The so-called "stagnant region" always occurs near the junction of a membrane or the surface of catalysts. Diagrammatically, the bulk

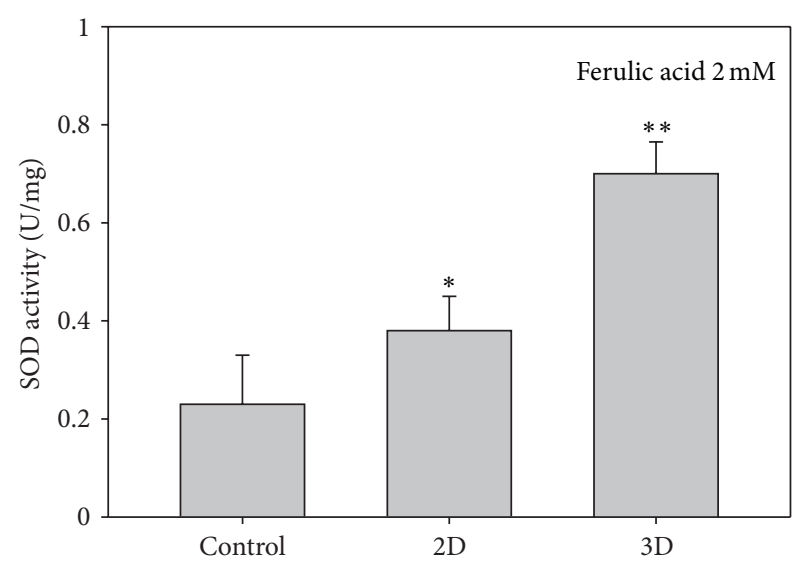

(a)

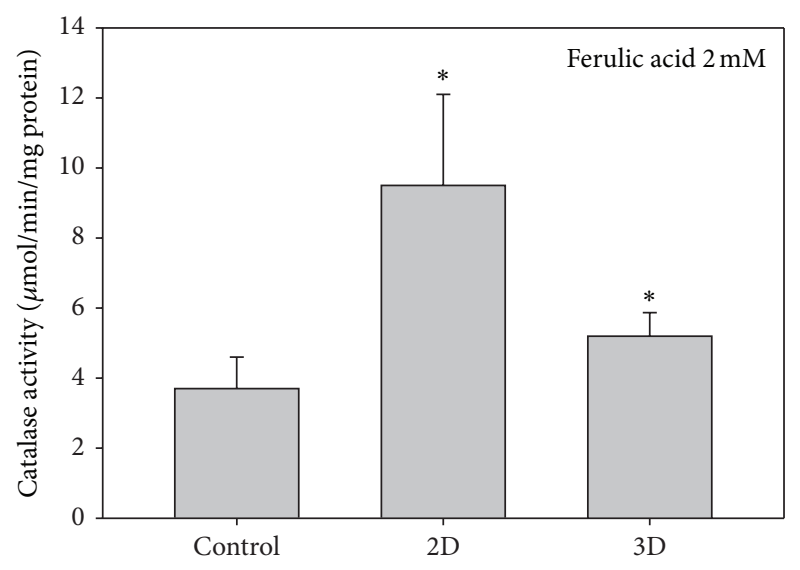

(b)

FIGURE 3: Variation of superoxide dismutase and catalase activities in T24 cell lines caused by 2D and 3D cultures. Superoxide dismutase (a) and catalase (b). Since the 2D without ferulic acid showed the lowest levels of SOD and catalase, we used the 2D without FA as the controls.

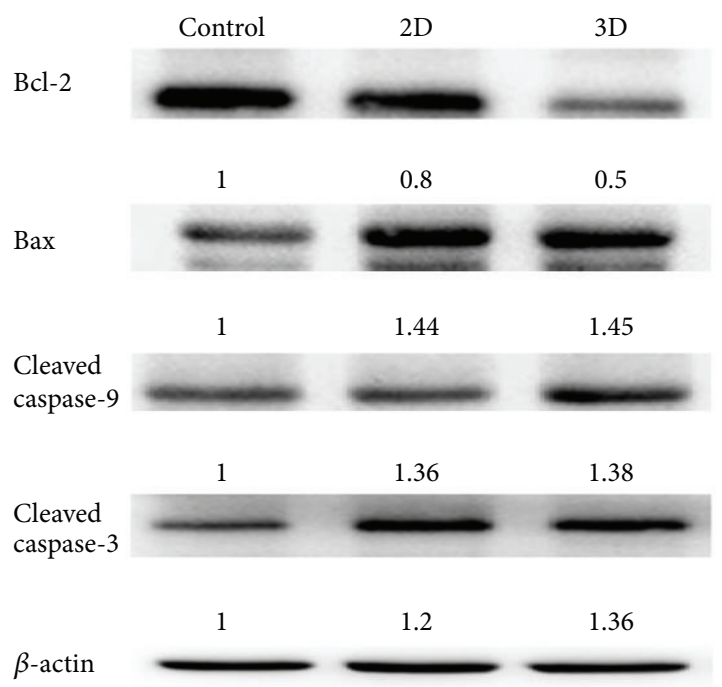

FIGURE 4: Western blot of Bcl-2, Bax, Bad, cleaved caspase-3, and cleaved caspase-9. 


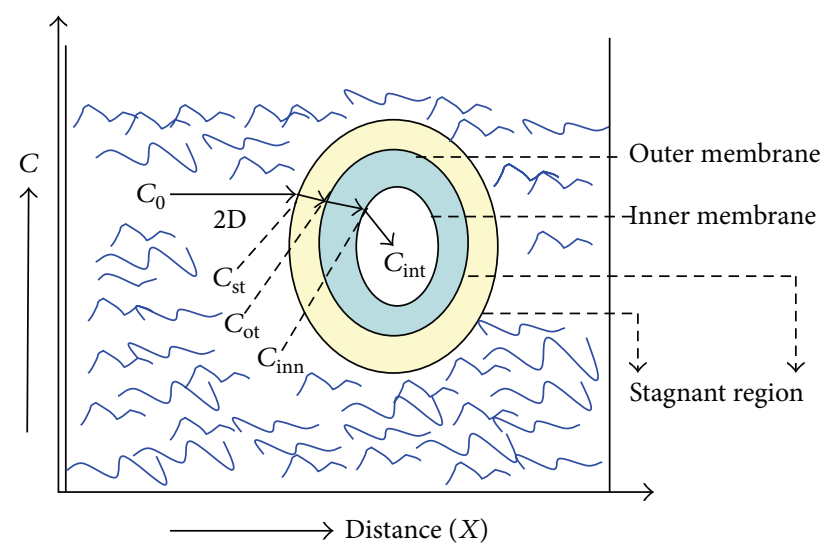

(a)

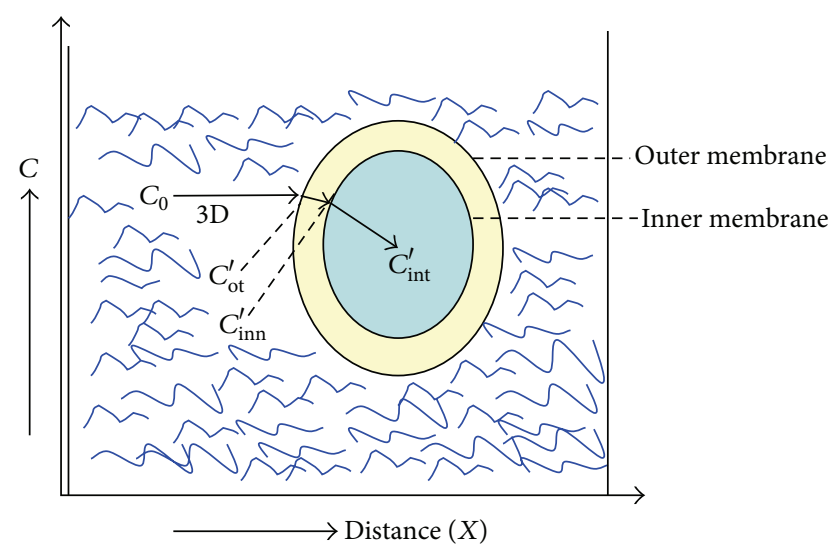

(b)

FIGURE 5: Diagrammatic model showing the difference of mass transports between the 3D (a) and 2D (b) cultures. In this model, due to the constantly free rolling of cells with the matrix in the medium for the 3D mass transport (a), the stagnant region could not be created. As contrast, the 2D mass transport (b) encounters two barriers: the stagnant region and the cell membrane. The stagnant region is a spontaneous barrier for mass transport adjacent to any membrane or catalyst surface. There would occur a concentration drop no sooner than the cells start to consume the medium.

concentration of ferulic acid in 2D-culture medium $\left(C_{0}\right)$ is first transported to the surface of stagnant region (denoted by $C_{s t}$, the concentration at the surface of stagnant region), dropping to $C_{\text {ot }}$ (the concentration at the outer membrane) (1) and then to $C_{\text {inn }}$ (the concentration at the junction of inner membrane; the subscript mem denotes "membrane") (2), and eventually is assumed by the cells, and hence the concentration drops to $C_{\text {int }}$ (the intracellular concentration) (3), (4) (Figure 5(a)) (1)-(4):

$$
\begin{gathered}
C_{\mathrm{ot}}=C_{\mathrm{o}}-\int_{t 1}^{t 2}\left(\frac{\delta C}{\delta x}\right)_{\mathrm{st}}\left(\frac{\delta x}{\delta t}\right)_{\mathrm{st}} \\
C_{\mathrm{inn}}=\left(\frac{C_{\mathrm{ot}}}{\delta x}\right)\left(\frac{\delta x}{\delta t}\right)_{\mathrm{mem}}, \\
\left(\frac{\delta C}{\delta t}\right)_{\mathrm{int}}=k_{2 \mathrm{D}}[C] .
\end{gathered}
$$

Integration of (3) yields

$$
\int_{C_{\mathrm{inn}}}^{C_{\mathrm{int}}} \frac{d C}{C}=k_{2 \mathrm{D}} \int_{t 1}^{t 2} d t
$$

where $K_{2 \mathrm{D}}$ is the consuming rate coefficient in $2 \mathrm{D}$ culture.

In contrast, due to the constantly free rolling of the cells with matrix in the medium, the stagnant region may disappear or be neglected in the $3 \mathrm{D}$ culture, where the bulk concentration $\left(C_{\mathrm{o}}\right)$ directly drops from the concentration at the outer membrane $\left(C_{\mathrm{ot}}^{\prime}\right)$ to the concentration at the inner membrane $\left(C_{\text {inn }}^{\prime}\right)(5)$ and then degraded to the intracellular concentration $\left(C_{\text {int }}\right)(6),(7)$ (Figure $\left.5(b)\right)(5)-(7)$ :

$$
\begin{gathered}
C_{\mathrm{inn}}=\left(\frac{C_{\mathrm{ot}}^{\prime}}{\delta x}\right)\left(\frac{\delta x}{\delta t}\right)_{\mathrm{mem}}, \\
\left(\frac{\delta C}{\delta t}\right)_{\mathrm{int}}=k_{3 \mathrm{D}}[C] .
\end{gathered}
$$

Integration of (6) yields

$$
\int_{C_{\mathrm{inn}}^{\prime}}^{C_{\mathrm{int}}^{\prime}} \frac{d C}{C}=k_{3 \mathrm{D}} \int_{t 1}^{t 2} d t,
$$

where $K_{3 \mathrm{D}}$ is the consuming rate coefficient in $3 \mathrm{D}$ culture.

Obviously without the presence of stagnant region in $3 \mathrm{D}$ culture, the mass transport will be less hindered. Hence, the cells in 3D culture would frequently "feel" or encounter higher toxicant concentration than the 2D culture. Moreover, the elongation of cells in 3D culture would provide a larger surface area for mass transport; as a consequence, the transport would fulfill the conditions $C_{\text {inn }}^{\prime} \gg C_{\text {inn }}$ and $C_{\text {int }}^{\prime} \gg C_{\text {int }}$, and the $3 \mathrm{D}$ cultures could be affected by ferulic acid at higher concentration. Thus although $3 \mathrm{D}$ culture may have many advantages: (i) largely reducing shear and turbulence generated by conventional stirred bioreactors, (ii) minimizing mechanical cell damage, and (iii) continuously free falling, promoting the assembly of 3D cellular aggregates which allow a microenvironment for more efficient cellto-cell interactions and exchange of growth factors [7], we suggest that the $3 \mathrm{D}$ RWV culture cannot be as real as the in vivo $3 \mathrm{D}$ growth.

To summarize, experiment with the T24 cell lines-ferulic acid $(2 \mathrm{mM})$ model reveled that FA showed different cytotoxicity on T24 cell line in the 2D and 3D culture systems. The cell shape was more elongated in the $3 \mathrm{D}$ culture. The SOD activity was higher, and conversely, the catalase activity was lower in the $3 \mathrm{D}$ culture. The antiapoptotic signal Bcl2 was downregulated, while all the apoptotic signals Bax, cleaved caspase-3, and cleaved caspase- 9 were upregulated by $\mathrm{FA}$, despite in the $2 \mathrm{D}$ or the $3 \mathrm{D}$ cultures. The overall apoptotic rate was higher for the $3 \mathrm{D}$ culture. To extend, more complicated pharmacokinetic and pharmacodynamic events could be expected in the in vivo $3 \mathrm{D}$ tissues.

\section{Conclusions}

Apparently, 3D culture has shown more powerful cytotoxicity than the $2 \mathrm{D}$ analogue. In cancer therapy, we encourage that 
the outcome of $2 \mathrm{D}$ culture must be corrected for the results to be applied to the in vivo cancer treatment.

\section{Disclosure}

The authors do not have any conflict of interests, and the authors have already disclosed any actual or potential conflict of interests including any financial, personal, or other relationships with other people or organizations within three years of beginning the submitted work that could inappropriately influence (bias) their work and related potential conflict of interests including employment, consultancies, stock ownership, honoraria, paid expert testimony, patent applications/registrations, and grants or other funding. Potential conflict of interests should be disclosed at the earliest possible stage.

\section{Acknowledgments}

The authors are grateful for the financial supports offered by the National Science Council of Taiwan (NSC 97-2320B-039-049-MY3, NSC 99-2320-B-039-034-, NSC 99-2320-B038-011-MY3, and NSC 101-2320-B-038-030) and Shin Kong Wu Ho-Su Memorial Hospital (SKH-TMU-93-37).

\section{References}

[1] S. Ou and K. C. Kwok, "Ferulic acid: pharmaceutical functions, preparation and applications in foods," Journal of the Science of Food and Agriculture, vol. 84, no. 11, pp. 1261-1269, 2004.

[2] J. A. Ross and C. M. Kasum, "Dietary flavonoids: bioavailability, metabolic effects, and safety," Annual Review of Nutrition, vol. 22, pp. 19-34, 2002.

[3] C. L. Hsieh, C. C. Peng, Y. M. Cheng et al., "Quercetin and ferulic acid aggravate renal carcinoma in long-term diabetic victims," Journal of Agricultural and Food Chemistry, vol. 58, no. 16, pp. 9273-9280, 2010.

[4] C. C. Peng, C. L. Hsieh, H. E. Wang, J. Y. Chung, K. C. Chen, and R. Y. Peng, "Ferulic acid is nephrodamaging while gallic acid is renal protective in long term treatment of chronic kidney disease," Clinical Nutrition, vol. 31, no. 3, pp. 405-414, 2012.

[5] R. Wang, J. Xu, L. Juliette et al., "Three-dimensional co-culture models to study prostate cancer growth, progression, and metastasis to bone," Seminars in Cancer Biology, vol. 15, no. 5, pp. 353-364, 2005.

[6] S. Y. Sung, C. L. Hsieh, D. Wu, L. W. K. Chung, and P. A. S. Johnstone, "Tumor microenvironment promotes cancer progression, metastasis, and therapeutic resistance," Current Problems in Cancer, vol. 31, no. 2, pp. 36-100, 2007.

[7] Synthecon, "Rotary cell culture system (RCCS 8DQ) from Synthecon, Biocompare," USA Synthecon, 8044 El Rio Houston, Tex, USA, 2010, http://www.synthecon.com/.

[8] J. Bubenik, M. Baresova, and V. Viklicky, "Established cell line of urinary bladder carcinoma (T24) containing tumour specific antigen," International Journal of Cancer, vol. 11, no. 3, pp. 765$773,1973$.

[9] J. M. Cherng, D. E. Shieh, W. Chiang, M. Y. Chang, and L. C. Chiang, "Chemopreventive effects of minor dietary constituents in common foods on human cancer cells," Bioscience, Biotechnology and Biochemistry, vol. 71, no. 6, pp. 1500-1504, 2007.
[10] C. C. Peng, K. C. Chen, R. Y. Peng, C. C. Chyau, C. H. Su, and H. M. Hsieh-Li, "Antrodia camphorata extract induces replicative senescence in superficial TCC, and inhibits the absolute migration capability in invasive bladder carcinoma cells," Journal of Ethnopharmacology, vol. 109, no. 1, pp. 93-103, 2007.

[11] H. W. Rhee, H. E. Zhau, S. Pathak et al., "Permanent phenotypic and genotypic changes of prostate cancer cells cultured in a three-dimensional rotating-wall vessel," In Vitro Cellular o Developmental Biology, vol. 37, no. 3, pp. 127-140, 2001.

[12] R. G. Hansford, B. A. Hogue, and V. Mildaziene, "Dependence of $\mathrm{H}_{2} \mathrm{O}_{2}$ formation by rat heart mitochondria on substrate availability and donor age," Journal of Bioenergetics and Biomembranes, vol. 29, no. 1, pp. 89-95, 1997.

[13] Y. Li, T. T. Huang, E. J. Carlson et al., "Dilated cardiomyopathy and neonatal lethality in mutant mice lacking manganese superoxide dismutase," Nature Genetics, vol. 11, no. 4, pp. 376381, 1995.

[14] S. Melov, S. R. Doctrow, J. A. Schneider et al., "Lifespan extension and rescue of spongiform encephalopathy in superoxide dismutase 2 nullizygous mice treated with superoxide dismutase-catalase mimetics," Journal of Neuroscience, vol. 21, no. 21, pp. 8348-8353, 2001.

[15] R. G. Alscher, N. Erturk, and L. S. Heath, "Role of superoxide dismutases (SODs) in controlling oxidative stress in plants," Journal of Experimental Botany, vol. 53, no. 372, pp. 1331-1341, 2002.

[16] G. F. Gaetani, A. M. Ferraris, M. Rolfo, R. Mangerini, S. Arena, and H. N. Kirkman, "Predominant role of catalase in the disposal of hydrogen peroxide within human erythrocytes," Blood, vol. 87, no. 4, pp. 1595-1599, 1996.

[17] E. M. Boon, A. Downs, and D. Marcey, "Proposed mechanism of catalase," Catalase: $\mathrm{H}_{2} \mathrm{O}_{2}: \mathrm{H}_{2} \mathrm{O}_{2}$ Oxidoreductase: Catalase Structural Tutorial, 2007, http://biology.kenyon.edu/BMB/ Chime/catalase/frames/cattx.htm\#Proposed\%20Mechanism\% 20of\%20Catalase.

[18] E. R. Werner and G. Werner-Felmayer, "Substrate and cofactor requirements of indoleamine 2,3-dioxygenase in interferongamma-treated cells: utilization of oxygen rather than superoxide," Current Drug Metabolism, vol. 8, no. 3, pp. 201-203, 2007.

[19] A. Poljak, R. Grant, C. J. D. Austin et al., "Inhibition of indoleamine 2,3 dioxygenase activity by $\mathrm{H}_{2} \mathrm{O}_{2}$," Archives of Biochemistry and Biophysics, vol. 450, no. 1, pp. 9-19, 2006.

[20] J. E. Bailey and D. F. Ollis, Biochemical Engineering Fundamentals International Edition, McGraw-Hill, New York, NY, USA, 198. 

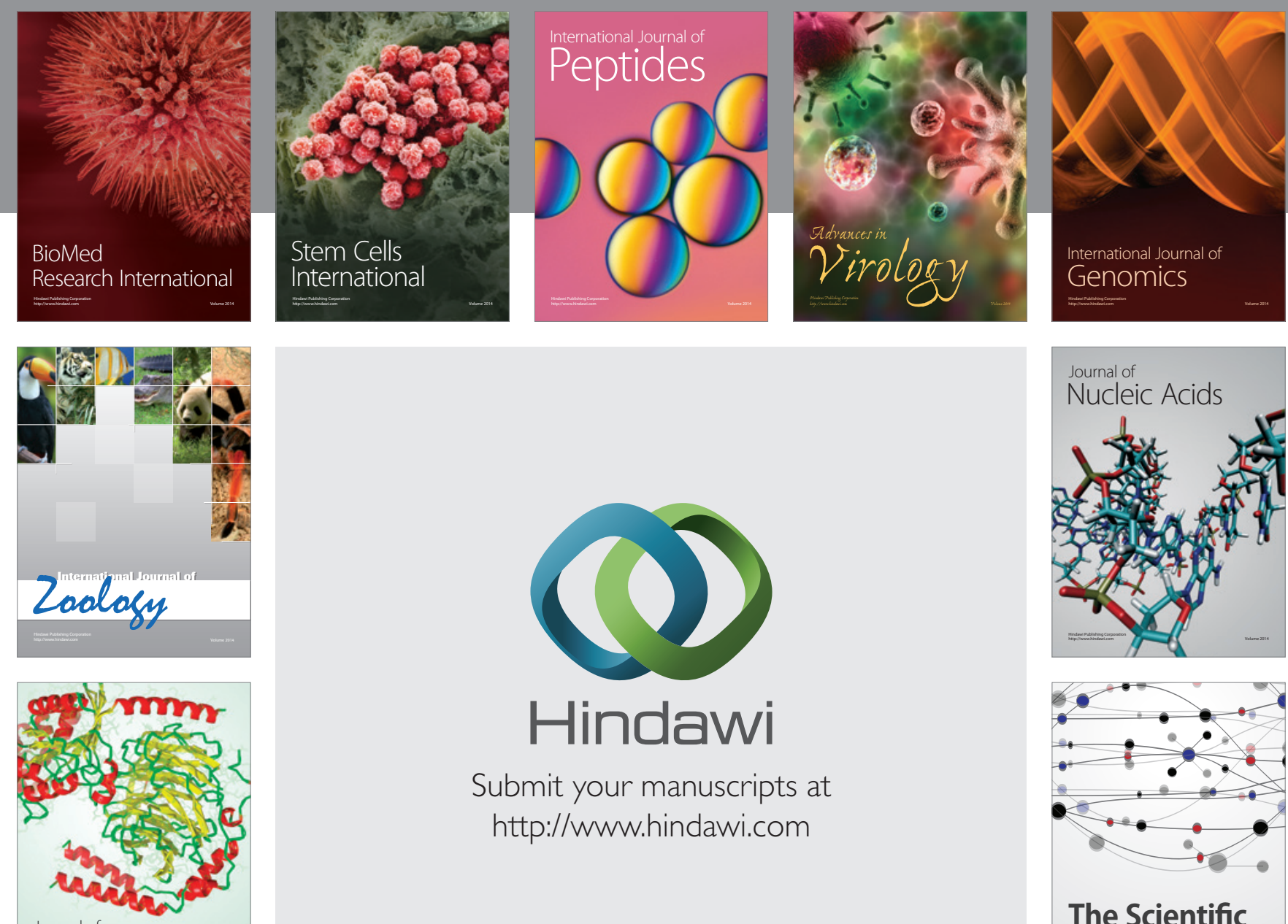

Submit your manuscripts at

http://www.hindawi.com

Journal of
Signal Transduction
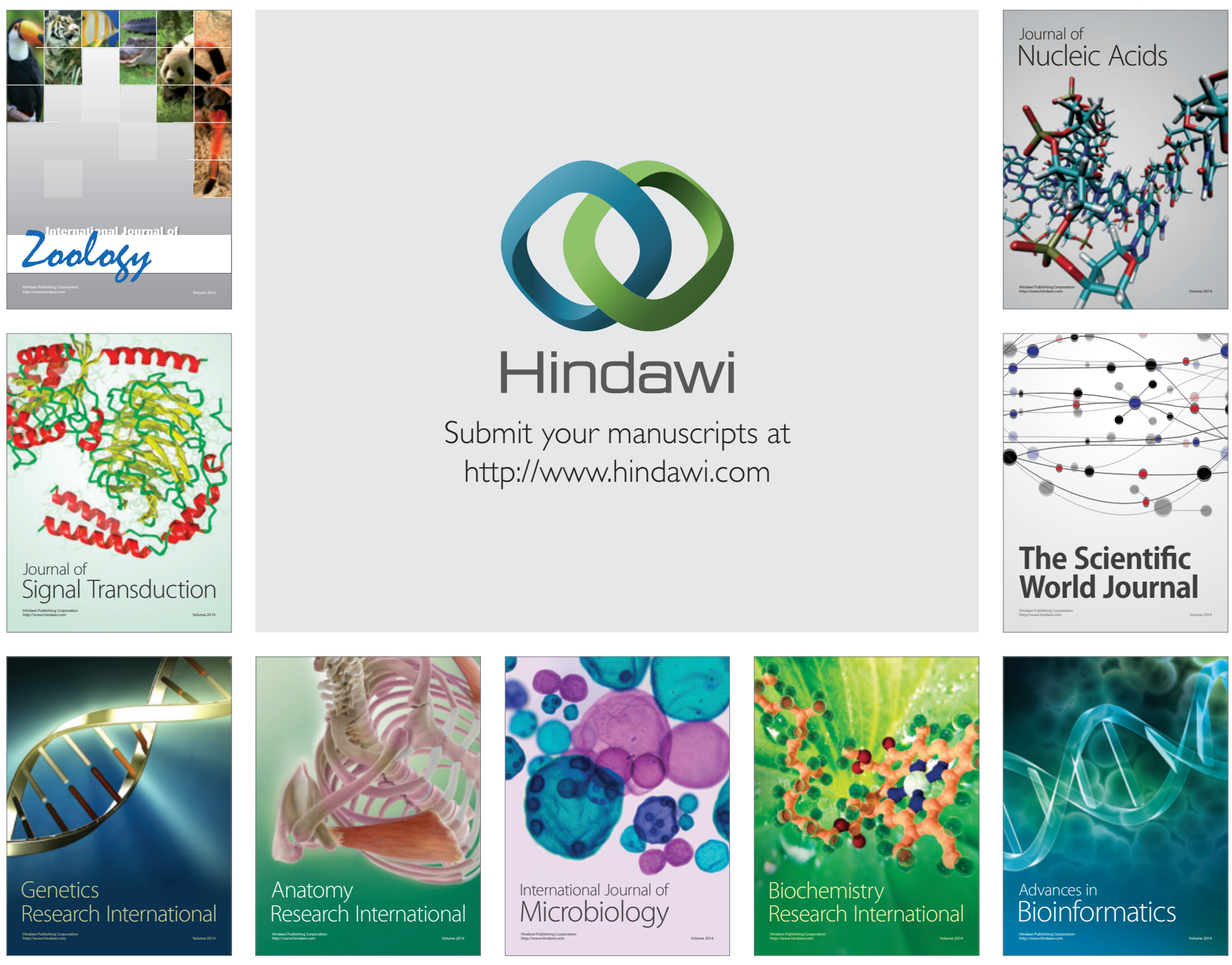

The Scientific World Journal
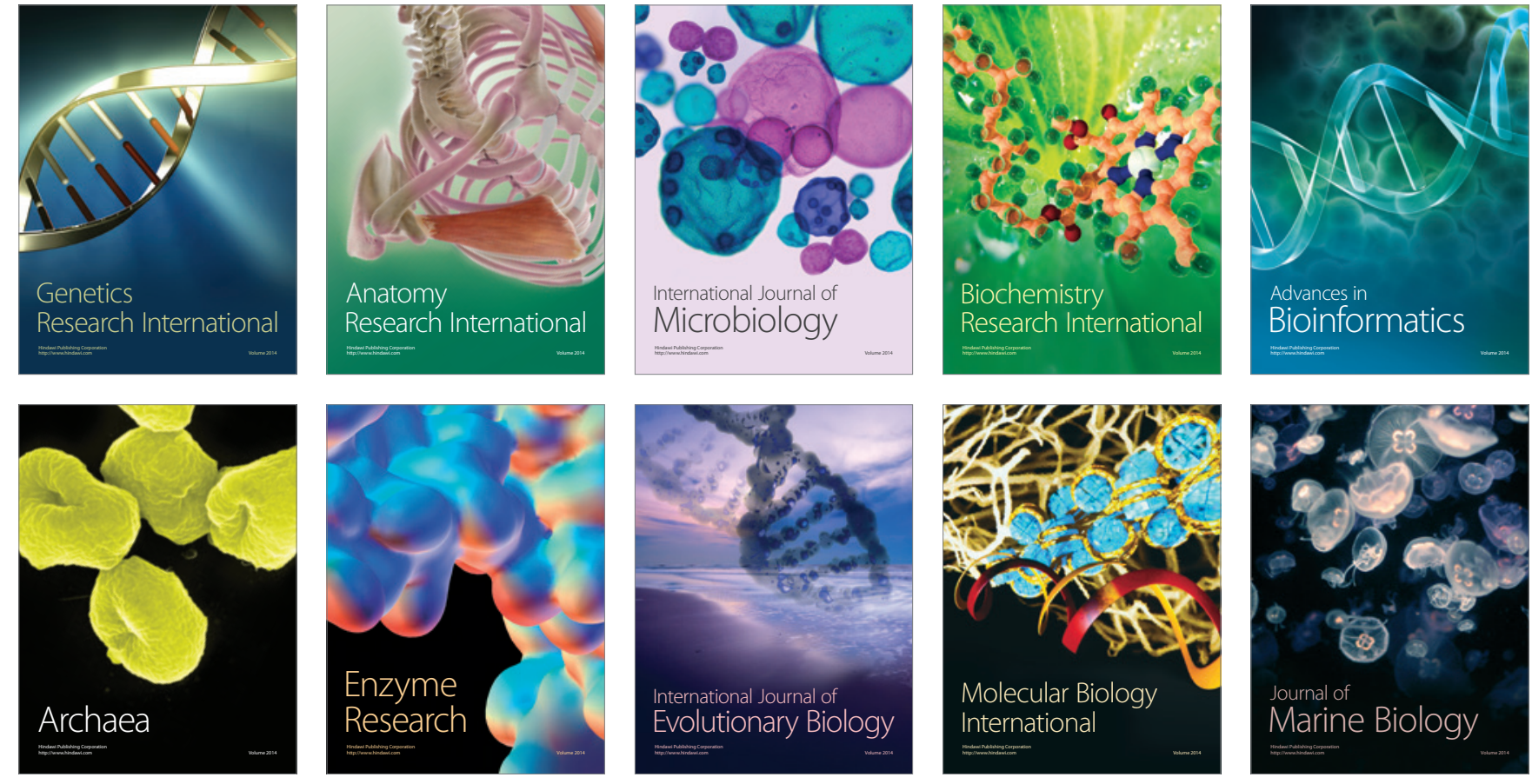